\title{
LC-MS/MS Method, Development and Validation to Determine Three Tetracyclines and Their Epimers in Shrimp Samples
}

\author{
B.SIDDA REDDY',2, Y.SUDHAKAR ${ }^{2}$, Y.SUBBA RAO ${ }^{3}$, \\ P.REDDY PRASAD ${ }^{1}$ and N.Y. SREEDHAR ${ }^{\star 1}$ \\ ${ }^{1}$ Department of Chemistry, S. V. University, Tirupati-517 502, A.P. India. \\ ${ }^{2}$ First Source Laboratory Solutions LLP (Analytical), Hyderabad, T.S, India. \\ ${ }^{3}$ DST-PURSE Centre, S. V. University, Tirupati- 517 502, A.P, India. \\ ${ }^{*}$ Corresponding author Email: sreedhar_ny@ rediffmail.com \\ http://dx.doi.org/10.13005/ojc/330539
}

(Received: March 29, 2017; Accepted: May 25, 2017)

\begin{abstract}
A modest liquid chromatography/tandem mass spectrometric method was developed and validated to determine three tetracycline antibiotics and their epimers tetracycline, oxytetracycline, chlortetracycline, 4-epi tetracycline, 4-epi oxytetracycline, 4-epi chlortetracycline in shrimp samples respectively. The procedure was involved the extraction of tetracyclines and its epimers from homogenized sample with EDTA-Mcllvaine buffer followed by solid phase extraction clean up with Oasis HLB cartridge. The analysis was carried out using Inertsil ODS-3V, 5 micron, 150×4.6 mm column and mobile phase consists of $5 \mathrm{mM}$ Oxalic acid in water $(\mathrm{A})$ and $0.1 \%$ formic acid in methanol $(B)$ in gradient mode at a flow rate of $0.8 \mathrm{~mL} /$ minutes. The final extracts were analyzed by the sensitive and selective LC/ESI/MS/MS operating in positive ion multiple reaction monitoring (MRM) mode.
\end{abstract}

Keywords: Tectracylines, Antibiotics, Shrimp, Liquid chromatography, Tandem mass spectrometry.

\section{INTRODUCTION}

Tetracyclines (TCs) are a family of broadspectrum antibiotics that are highly effective against a number of gram-positive and gram-negative bacteria, these antibiotics used worldwide to control bacterial infection and promote aquatic production ${ }^{1-4}$. Therefore, the easy availability and efficiency for the treatment of bacterial infected disease, they were widely used in animal husbandry and aquaculture ${ }^{5-7}$. As with other veterinary antibiotics, when tetracycline is used in food animals, it has the potential to generate drug residues in the animals and animal products which can lead to increases in microbial resistance. Due to the misuse, the antibiotic residues in products of aquatic animal origin (Fish, Shrimp etc.) brought a concern to consumers. The residue of this kind of drugs can be directly toxic or else cause allergic reactions in some hypersensitive individuals ${ }^{8}$. Thus in order to protect human health, the European Union and other regulatory authorities worldwide have established maximum residue limits (MRL) for antibiotic residues in animal products entering the 
human food chain. European Union Commission Regulation 37/2010/EC establishes the MRLs for tetracyclines are $100 \mu \mathrm{g} / \mathrm{kg}(\mathrm{ppb})$ in muscle and $300 \mu \mathrm{g} / \mathrm{kg}(\mathrm{ppb})$ in liver for all food producing species $^{9}$.

In this respect, it is of great interest to develop analytical procedures capable of determining with good accuracy and sensitivity, the animal tissue concentrations of TCs and to evaluate their presence in edible animal products to protect human health. Accurate monitoring of chemical residue levels in food and agriculture products is essential to assure the safety of the food supply and manage global health risks. The analysis of chemical residues requires techniques sensitive enough to detect and quantify contaminants at or below the maximum residue limit (MRL) of the compound in a given sample matrix. In addition, because of increased food safety regulations and the growing numbers of samples to be analyzed, it is critical that the analytical techniques provide high sample throughput. Several analytical methods have been successfully proposed for the determination of TCs in various matrixes. In particular liquid chromatography in reverse phase mode (RP-HPLC) coupled with different detection systems such as UV ${ }^{10-15}$, PDA ${ }^{16-18}$, fluorescence is widely used in routine analysis of TCs in different matrixes ${ }^{19,20}$. On the other hand, during last decade LC-MS/MS methods have been developed and implemented effectively for the determination of TCs mainly due to the known advantages of MS detection over conventional detection methods ${ }^{21-28}$. However based on the author's knowledge no LC-MS/MS method with full validation

\section{Tetracycline-1}

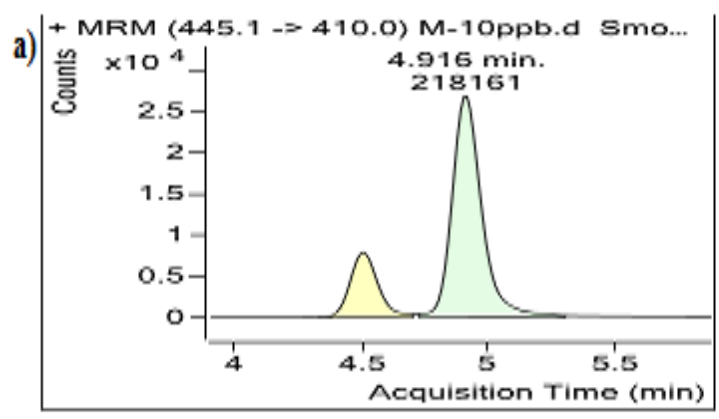

has been reported for the determination of tetracycline antibiotics along with their epimers in shrimp samples. Therefore the aim of this study is to develop rapid, simple and reliable LC-MS/MS method for the determination of three tetracyclines (chlortetracycline, oxytetracycline and tetracycline) along with their epimers (4-epi chlortetracycline, 4-epi oxytetracycline and 4-epi tetracycline) in shrimp samples.

\section{EXPERIMENTAL}

\section{Chemicals and materials}

Methanol, acetonitrile and ammonium acetate were purchased from Sigma-Aldrich. Ethylacetate was purchased from Merck \& Co. All the other inorganic chemicals and organic solvents were of analytical reagent grade or higher. Standards of tetracycline, chlortetracycline, oxytetracycline, 4-epi chlortetracycline, 4-epi oxytetracycline, 4-epi tetracycline were acquired from Sigma-Aldrich.

\section{Preparation of stock solution (standard solution)}

The standard stock solutions were prepared by accurately weighed $10 \mathrm{mg}$ of each standard and is transferred into $10 \mathrm{~m} \mathrm{I} \mathrm{volumetric}$ flask and made up to the mark with HPLC grade methanol and stored at $-20^{\circ} \mathrm{C}$. After proper dilution these stock solutions were used to prepare calibration curve and to fortify the blank shrimp samples to perform the recovery study.

\section{Shrimp samples}

Shrimp samples were collected from local market and stored at $20^{\circ} \mathrm{C}$ before the analysis.

\section{Tetracycline-2}

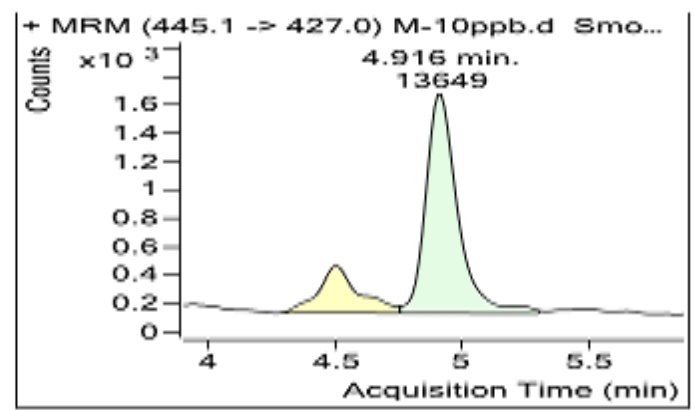




\section{4-Epi Tetracycline-1}

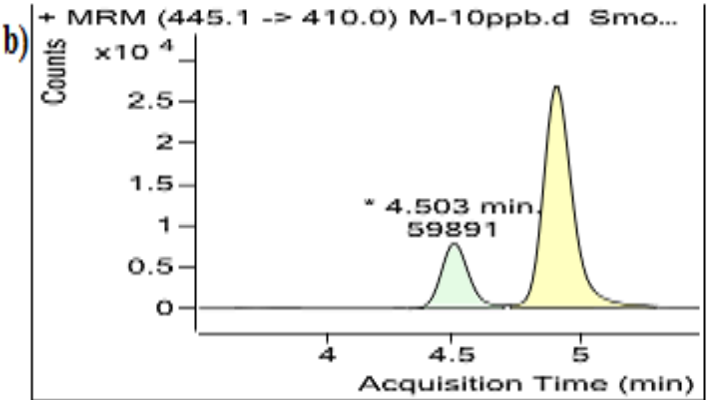

\section{Oxyrtetracycline-1}

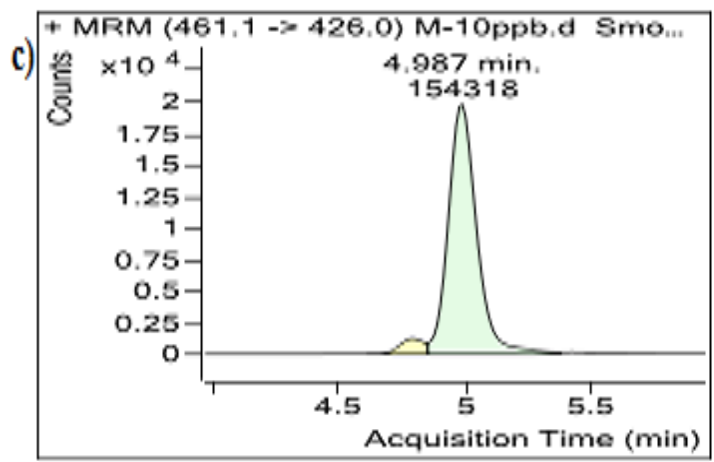

\section{4-Epi Oxytetracycline-1}

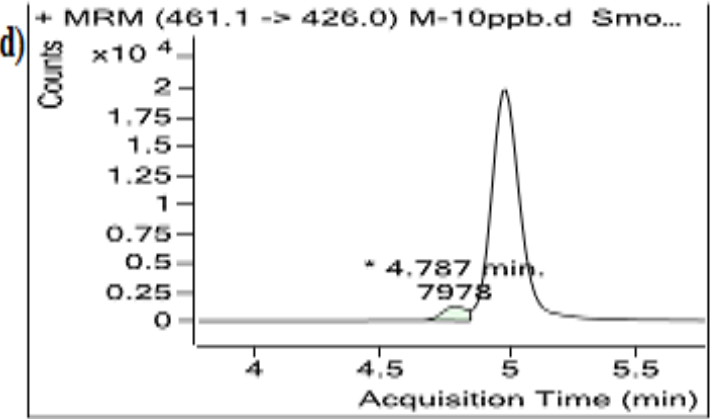

Equipment

Liquid chromatography

The extracts were separated on Inertsil ODS-3V 5 micron, $150 \times 4.6$ mm HPLC column using Agilent 1290 HPLC system with a Binary pump, an auto sampler with temperature control, and a column oven kept at $30{ }^{\circ} \mathrm{C}$. Sample aliquots of $5 \mu \mathrm{L}$ were injected to the HPLC column, mobile phase consists of $5 \mathrm{mM}$ Oxalic acid in Water $(\mathrm{A})$ and $0.1 \%$ Formic acid in Methanol (B) in gradient mode with a flow rate of $0.8 \mathrm{ml} /$ minutes. The gradient programme was given in the Table 1. The resultant chromatograms are shown in Figure. 1.

\section{4-Epi Tetracycline-2}

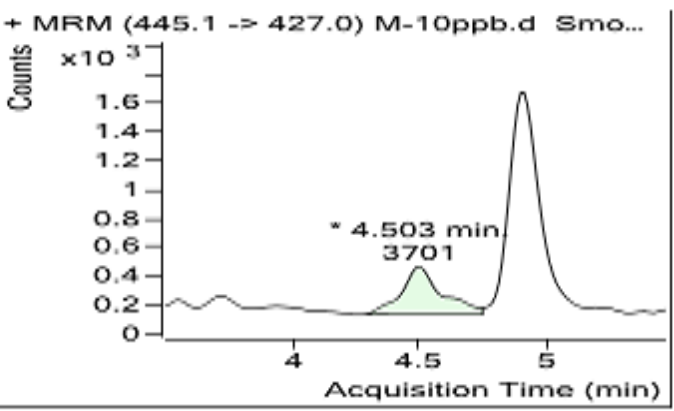

\section{Oxyrtetracycline-2}

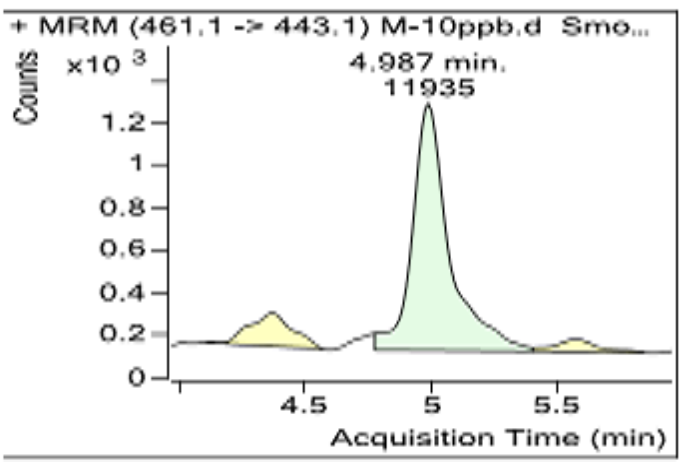

\section{4-Epi Oxytetracycline-2}

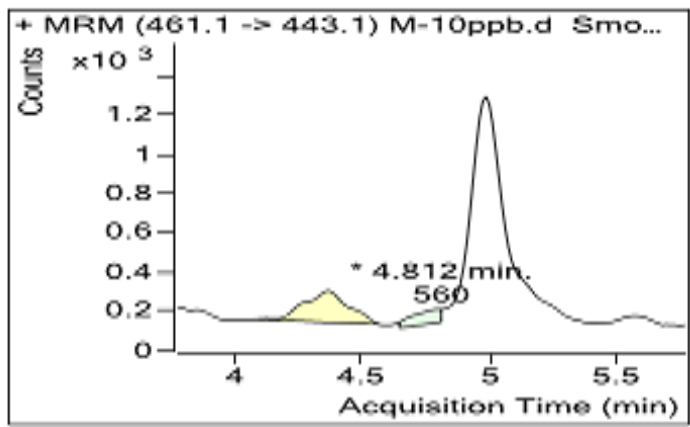

Table. 1: Gradient Program

\begin{tabular}{cccc} 
S.No. & $\begin{array}{c}\text { Time } \\
(\mathrm{min})\end{array}$ & $\begin{array}{c}\% \text { Composition } \\
\text { of A }\end{array}$ & $\begin{array}{c}\% \text { Composition } \\
\text { of B }\end{array}$ \\
\hline 1 & 0 & 90 & 10 \\
2 & 8.0 & 10 & 90 \\
3 & 8.1 & 90 & 10 \\
4 & 10.0 & 90 & 10
\end{tabular}




\section{Chlortetracycline-1}

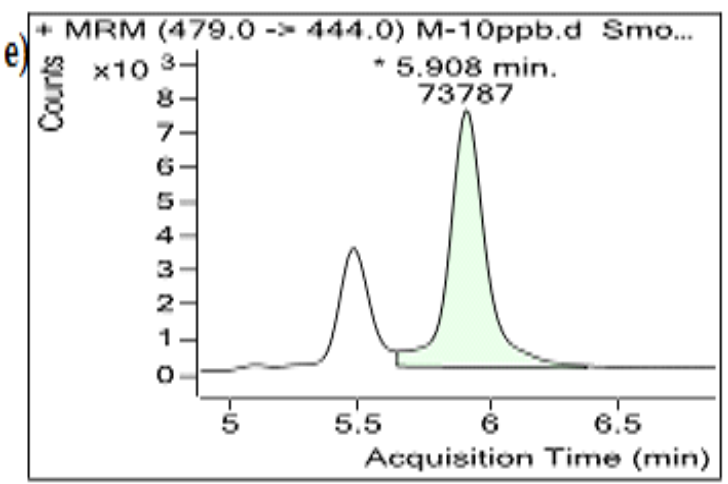

4-Epi Chlortetracycline-1

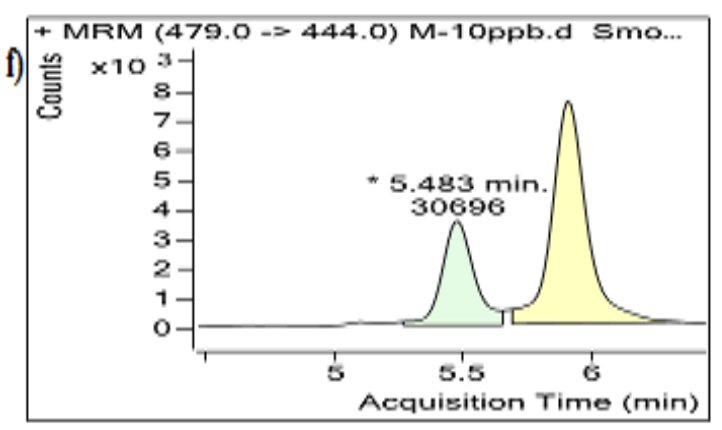

\section{Chlortetracycline-2}

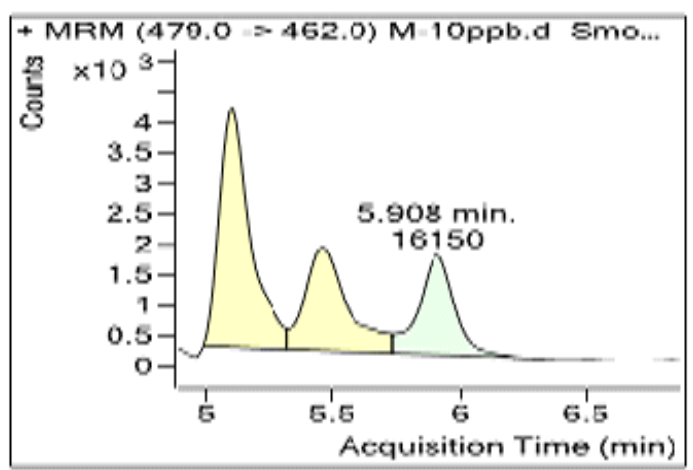

4-Epi Chlortetracycline-2

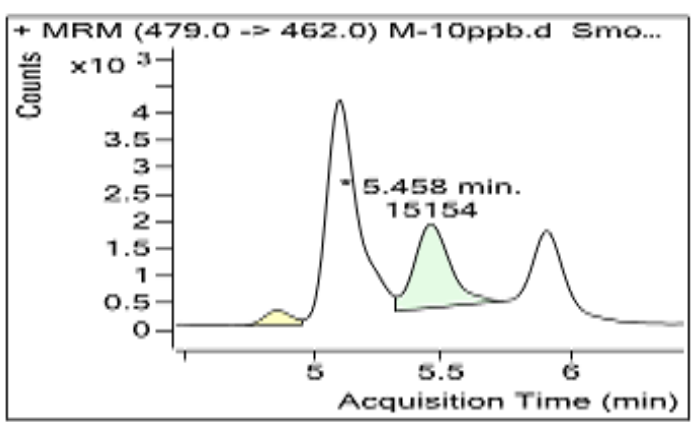

Fig. 1. MRM Chromatograms of TC (a), 4-epiTC (b), ОтC(c), 4-еріОтC (d), СтC (e), 4-ері-СтC (f).

\section{Tandem MS analysis}

The flow from the LC column was transferred to a triple quadrupole mass spectrometer (Agilent 6470) equipped with an ESI source. The analysis was performed in positive polarity mode for all compounds. Instrument control, data acquisition and evaluation were done with Mass Hunter software, Version B.06.00. Determination was performed by two MRM (multiple reaction monitoring) transitions (one for quantitation and second one for conformation) mode, the MRM dynamics were given in the table 2 . The typical source parameters were: Gas Temperature: $350^{\circ} \mathrm{C}$, Gas flow: 10 l/min. Nebulizer: 45 psig, Sheath Gas Temperature: $400^{\circ} \mathrm{C}$, Sheath Gas flow: 11 L/min. V Cap: 3500 V, Nozzle Voltage: 0V.

Table. 2: Multiple Reaction Monitoring transitions (Dynamic MRM)

\begin{tabular}{|c|c|c|c|c|c|}
\hline Analyte(Transition) & Parent ion $\left(Q_{1}\right)$ & Product ion $\left(\mathrm{Q}_{3}\right)$ & Fragmentor (Volts) & CE (Volts) & CAV \\
\hline 4-Epi Chlortetracycline-1 & 479 & 444 & 100 & 28 & 7 \\
\hline 4-Epi Chlortetracycline-2 & 479 & 462 & 100 & 18 & 7 \\
\hline 4-Epi Oxytetracycline-1 & 461.1 & 426 & 110 & 10 & 7 \\
\hline 4-Epi Oxytetracycline-2 & 461.1 & 443.1 & 110 & 15 & 7 \\
\hline 4-Epi Tetracycline-1 & 445.1 & 410 & 110 & 10 & 7 \\
\hline 4-Epi Tetracycline-2 & 445.1 & 427 & 110 & 15 & 7 \\
\hline Chlortetracycline-1 & 479 & 444 & 100 & 15 & 7 \\
\hline Chlortetracycline-2 & 479 & 462 & 100 & 18 & 7 \\
\hline Oxyrtetracycline-1 & 461.1 & 426 & 110 & 10 & 7 \\
\hline Oxyrtetracycline-2 & 461.1 & 443.1 & 110 & 15 & 7 \\
\hline Tetracycline-1 & 445.1 & 410 & 110 & 10 & 7 \\
\hline Tetracycline-2 & 445.1 & 427 & 110 & 15 & 7 \\
\hline
\end{tabular}




\section{RESULTS AND DISCUSSION}

\section{Sample preparation}

Collected blank shrimp samples were cleaned thoroughly, cut in to small pieces and homogenized. $5 \mathrm{~g}$ of homogenized sample was weighed and taken into $50 \mathrm{~mL}$ centrifuge tube, to this $15 \mathrm{~mL}$ of Disodium EDTA Mcllvaine buffer is added, vortexed for $5 \mathrm{~min}$. separated the aqueous layer by centrifuging the sample with $4500 \mathrm{rpm}$ at $4{ }^{\circ} \mathrm{C}$. The supernatant was transferred into a clean tube and repeated the extraction by adding $15 \mathrm{ml}$ of Mcllvaine buffer and combined the aliquots.

SPE Clean UP: The aqueous layer was applied to on preactivated with methanol $(6 \mathrm{ml})$ water $93 \mathrm{ml}$ ) and Mcvallin buffer (6 ml) HLB 500 $\mathrm{mg} / 6 \mathrm{cc}$ spe cartridge previously activated with methanol and milli-Q water. After sample loading, the cartridge was given washings with Milli-Q water $(6 \mathrm{ml})$ and dried the cartridge with the help of vacuum. TC antibiotics were eluted with methanol $(6 \mathrm{ml})$ and the eluent was evaporated under a stream of nitrogen at $35^{\circ} \mathrm{C}$, and the residue was dissolved in $2 \mathrm{~mL} 0.1 \%$ Formic acid: Methanol (9:1) and analyse on LC-MS/MS.

\section{Method validation}

The proposed method was validated for system suitability, specificity, selectivity, sensitivity (limits of detection and limit of quantification), recovery (accuracy), ruggedness, decision limit (CC $\alpha)$ and detection capability (CC $\beta$ ) according to 2002/657/EC decision.

\section{System suitability}

System suitability was performed by injecting six replicates of known concentration of standard solution. The results were within the acceptance criteria i.e. \% RSD of area was less than $5 \%$. The results have been given in Table 3 .

\section{Specificity}

Specificity was performed by injecting 20 representative blank samples and sample spiked at MRL, observed that there was no interferences at the retention of analyte. The results have been given in Table 4.

\section{Calibration Curve (Linearity)}

Linearity was checked for each compound using six standard solutions with concentrations ranging in concordance with the level of the maximum residue limit (MRL). Three sets Linearity was established using matrix-matched calibration curves. Calibration curves were prepared at levels of matrix blank, 10 ppb, 50 ppb, 100 ppb, 150 ppb and $200 \mathrm{ppb}$ in Shrimp and analyzed with each batch. The results of coefficient of determination greater than 0.99 and the results have been shown in Table 5 and Figure. 2.

Table. 3: System suitability

\begin{tabular}{|c|c|c|c|c|c|c|c|c|c|c|}
\hline $\begin{array}{l}\text { S. } \\
\text { No. }\end{array}$ & $\begin{array}{l}\text { Analyte } \\
\text { Name }\end{array}$ & Rep-1 & Rep-2 & Rep-3 & Rep-4 & Rep-5 & Rep-6 & Mean & SD & \%RSD \\
\hline 1 & $\begin{array}{l}\text { 4-epi } \\
\text { chlortetra } \\
\text { cycline }\end{array}$ & $\begin{array}{c}89251 \\
1\end{array}$ & $\begin{array}{c}94573 \\
8\end{array}$ & $\begin{array}{c}93723 \\
6\end{array}$ & $\begin{array}{c}92212 \\
7\end{array}$ & $\begin{array}{c}10009 \\
41\end{array}$ & $\begin{array}{c}10040 \\
36\end{array}$ & $\begin{array}{c}95043 \\
2\end{array}$ & $\begin{array}{c}44219 . \\
1341\end{array}$ & 4.65 \\
\hline 2 & $\begin{array}{l}\text { 4-epi } \\
\text { oxytetra } \\
\text { cycline }\end{array}$ & $\begin{array}{c}39752 \\
4\end{array}$ & $\begin{array}{c}37778 \\
3\end{array}$ & $\begin{array}{c}38718 \\
9\end{array}$ & $\begin{array}{c}37147 \\
8\end{array}$ & $\begin{array}{c}35916 \\
9\end{array}$ & $\begin{array}{c}37370 \\
2\end{array}$ & $\begin{array}{c}37780 \\
7\end{array}$ & $\begin{array}{c}13274 . \\
4630\end{array}$ & 3.51 \\
\hline 3 & $\begin{array}{l}\text { 4-epi } \\
\text { tetracycline }\end{array}$ & $\begin{array}{c}16513 \\
14\end{array}$ & $\begin{array}{c}16849 \\
29\end{array}$ & $\begin{array}{c}16682 \\
18\end{array}$ & $\begin{array}{c}17149 \\
73\end{array}$ & $\begin{array}{c}17700 \\
66\end{array}$ & $\begin{array}{c}17543 \\
06\end{array}$ & $\begin{array}{c}17073 \\
01\end{array}$ & $\begin{array}{c}47687 . \\
0313\end{array}$ & 2.79 \\
\hline 4 & $\begin{array}{l}\text { Chlortetra } \\
\text { cycline }\end{array}$ & $\begin{array}{c}19228 \\
54\end{array}$ & $\begin{array}{c}18927 \\
95\end{array}$ & $\begin{array}{c}18955 \\
96\end{array}$ & $\begin{array}{c}18921 \\
09\end{array}$ & $\begin{array}{c}19675 \\
35\end{array}$ & $\begin{array}{c}19130 \\
28\end{array}$ & $\begin{array}{c}19139 \\
86\end{array}$ & $\begin{array}{c}29027 . \\
5990\end{array}$ & 1.52 \\
\hline 5 & $\begin{array}{l}\text { Oxytetra } \\
\text { cycline }\end{array}$ & $\begin{array}{c}32507 \\
17\end{array}$ & $\begin{array}{c}32681 \\
98\end{array}$ & $\begin{array}{c}33469 \\
82\end{array}$ & $\begin{array}{c}32859 \\
48\end{array}$ & $\begin{array}{c}33841 \\
71\end{array}$ & $\begin{array}{c}32587 \\
69\end{array}$ & $\begin{array}{c}32991 \\
31\end{array}$ & $\begin{array}{c}54083 . \\
7727\end{array}$ & 1.64 \\
\hline 6 & Tetra & 37211 & 38467 & 38075 & 38720 & 39351 & 38788 & 38435 & 73124 & 1.90 \\
\hline
\end{tabular}


Table. 4: Specificity

S.No. Analyte Name

Average area of analyte in

Average of $L O Q$ area blank samples

\begin{tabular}{llcc}
\hline 1 & 4-epi chlortetracycline & 444.9 & 30696 \\
2 & 4-epi oxytetracycline & 1821.4 & 7978 \\
3 & 4-epi tetracycline & 238.8 & 59891 \\
4 & Chlortetracycline & 2220.9 & 73787 \\
5 & Oxytetracycline & 1940.8 & 154318 \\
6 & Tetracycline & 1973.5 & 218161 \\
\hline
\end{tabular}

Table. 5: Linearity Results

\begin{tabular}{llcc}
\hline S.No. & Compound & Slope $(\mathbf{m})$ & Coefficient of determination $\left(\mathbf{R}^{2}\right)$ \\
\hline 1 & 4-epi chlortetracycline & 4472.684 & 0.998901 \\
2 & 4-epi oxytetracycline & 1986.989 & 0.99912 \\
3 & 4-epi tetracycline & 9320.932 & 0.998678 \\
4 & Chlortetracycline & 8843.196 & 0.998558 \\
5 & Oxytetracycline & 15773.01 & 0.998562 \\
6 & Tetracycline & 20477.41 & 0.998768 \\
\hline
\end{tabular}

(a) Linearity of Tetracyline

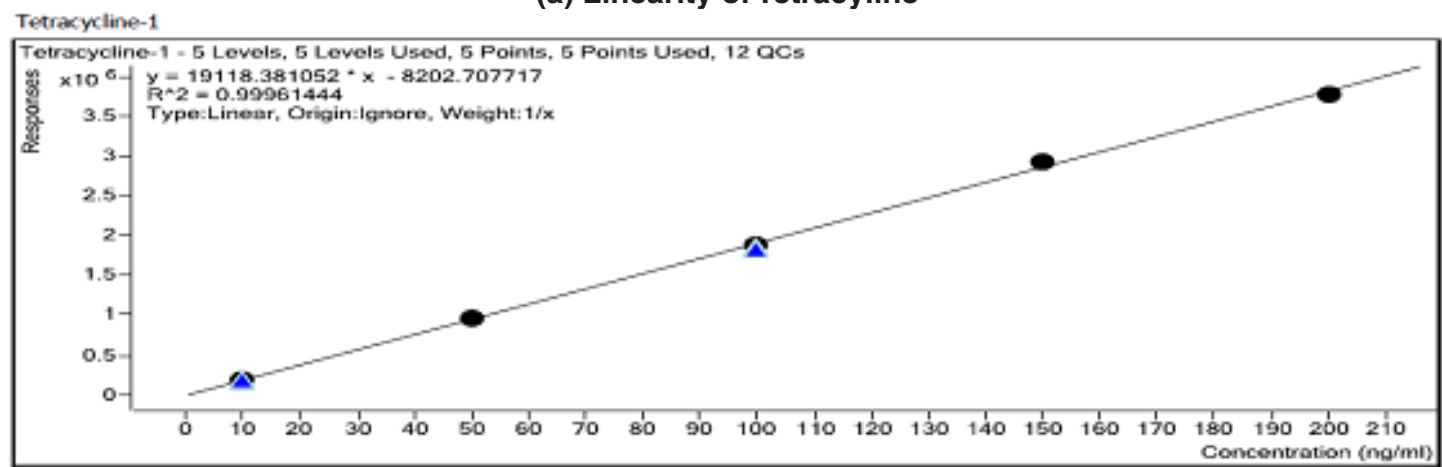

(d) Linearity of 4-epi-Oxy Tetracycline

4-Epi Tetracycline-1

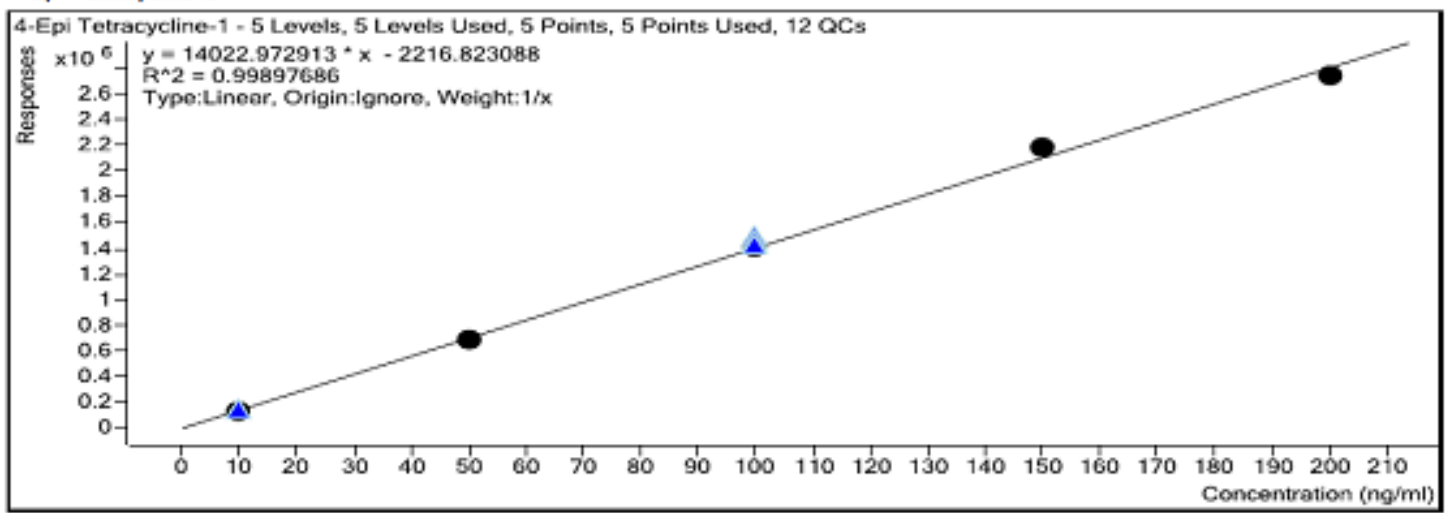




\section{(c)Linearity of Oxy Tetracycline}

Oxyrtetracycline-1

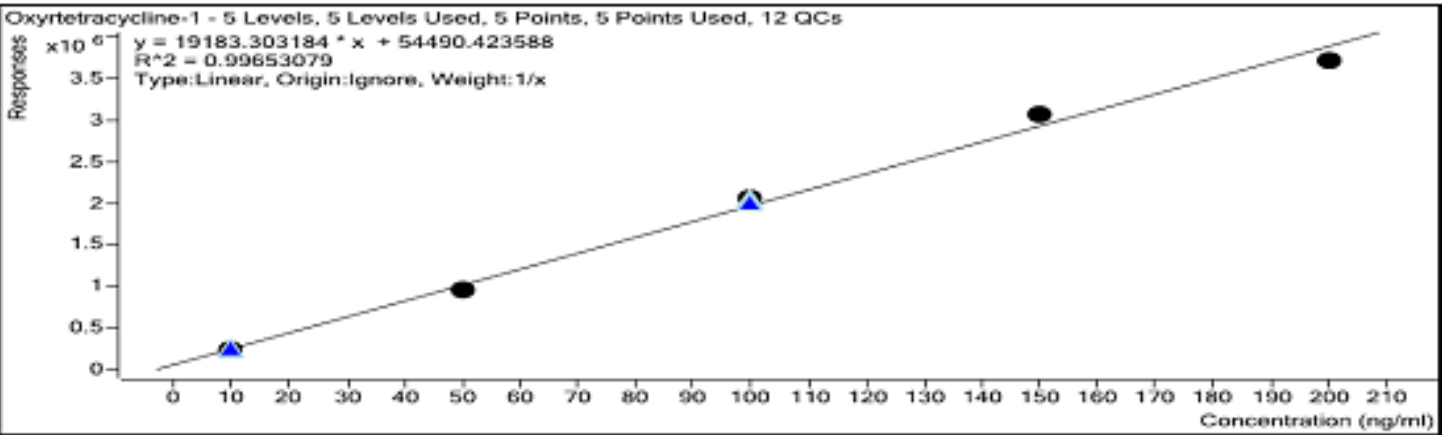

(d) Linearity of 4-epi-Oxy Tetracycline

4-Epi Oxytetracycline-1

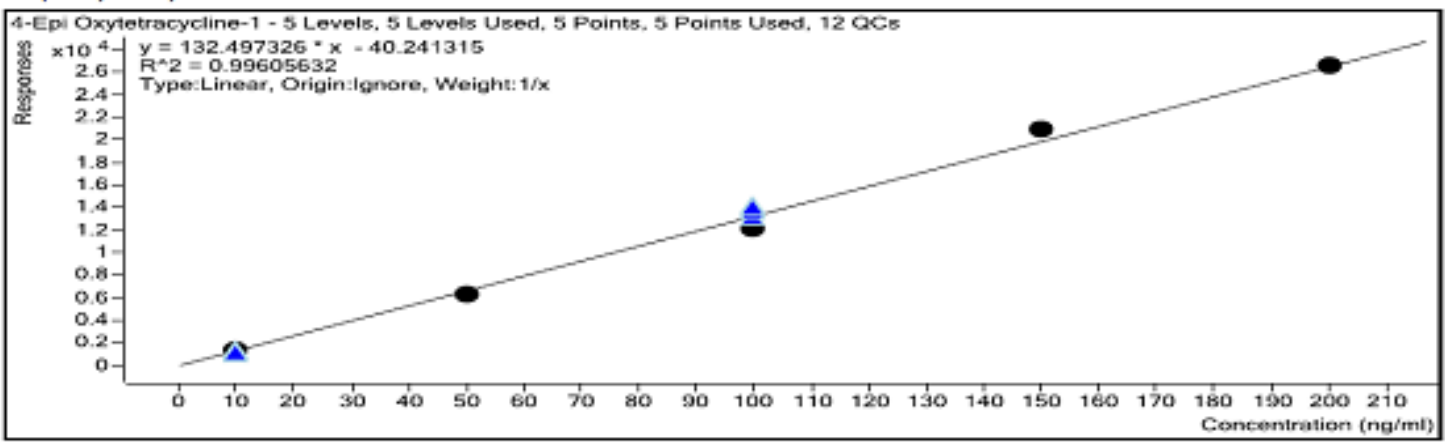

(e)Linearity of Chlorotetracycline

Chlortetracycline-1

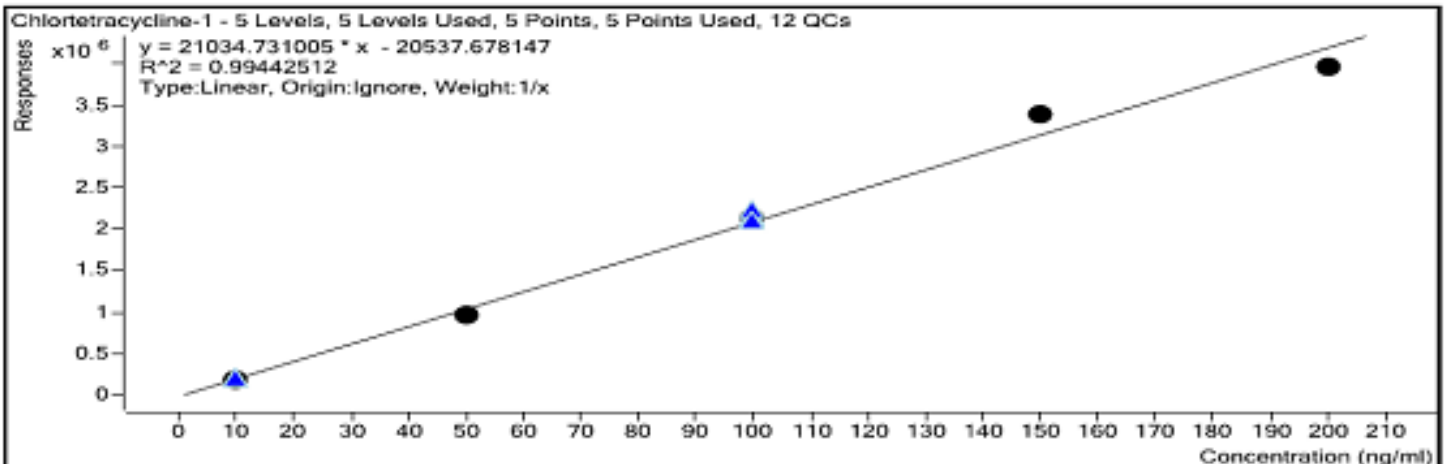

(f) Linearity of 4-epi-Chlorotetracycline

4-Epi Chlortetracycline-1

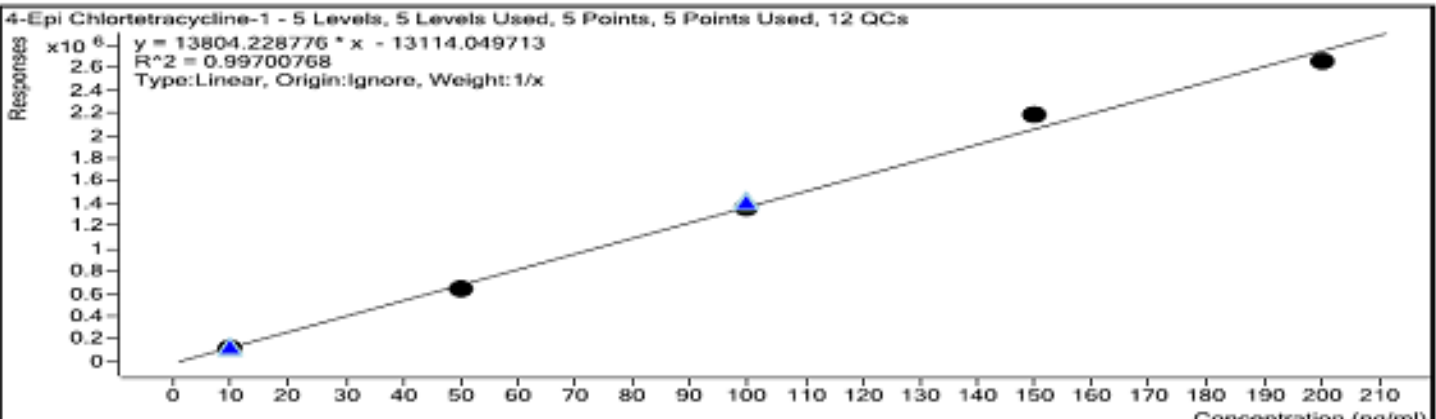

Fig. 2. Linearity diagram of TC (a), 4-epi TC (b), OTC(c), 4-ері ОTC (d), CTC (e), 4-ерi-CTC (f). 
Table. 6: Limit of Detection and Limit of Quantification

\begin{tabular}{llcccc}
\hline S.No. & Compound & SD (STEYX) & Slope & LOD & LOQ \\
\hline 1 & 4-epi chlortetracycline & 24310.06 & 4472.684 & 17.93625 & 54.35229 \\
2 & 4-epi oxytetracycline & 9663.506 & 1986.989 & 16.04919 & 48.63392 \\
3 & 4-epi tetracycline & 55580.3 & 9320.932 & 19.67775 & 59.62955 \\
4 & Chlortetracycline & 55064.58 & 8843.196 & 20.54835 & 62.26774 \\
5 & Oxytetracycline & 98082.35 & 15773.01 & 20.52061 & 62.18366 \\
6 & Tetracycline & 117829.7 & 20477.41 & 18.98863 & 57.54131 \\
\hline
\end{tabular}

\section{Limit of Detection and Limit of Quantification}

Calculated the Limit of Detection (LOD) and Limit of Quantification (LOQ) by using standard deviation (STEYX) of the response and the slope of the linearity and the obtained LOD and LOQ values are given in the Table 6 .

\section{Repeatability and Within Laboratory Reproducibility}

Repeatability was performed by injecting seven spiked samples at $50 \mathrm{ppb}, 100 \mathrm{ppb}$ and 150 $\mathrm{ppb}$ and calculated the mean, standard deviation and $\%$ RSD. The results were within the acceptance criteria i.e. \% RSD of area $\leq 20$. For within Laboratory reproducibility the above procedure was performed and calculated the mean, standard deviation and \%RSD for all the analyses at $50 \mathrm{ppb}(0.5 \mathrm{MRL}), 100$ $\mathrm{ppb}$ (MRL) and $150 \mathrm{ppb}$ (1.5 MRL).

\section{Recovery/Accuracy (Trueness)}

Recovery was performed by injecting seven spiked samples at $50 \mathrm{ppb}, 100 \mathrm{ppb}$ and 150 $\mathrm{ppb}$ and calculated the mean, the standard deviation and the coefficient of variance for these concentrations, calculate the recovery as accuracy (trueness) by dividing the detected mean concentration by the fortified value and multiply by 100 and the results are given in Table 7.

\section{Ruggedness}

Ruggedness was performed by injecting seven spiked samples with two different analysts and two different lots of extraction solvents at permitted level. Calculated the Mean, standard deviation and \% RSD. The results were within the acceptance criteria i.e. \% RSD of area $\leq 7$ and the results were given in Table-8.

\section{Decision Limit (CC $\alpha)$}

Decision limit was performed by injecting seven spiked samples at $50 \mathrm{ppb}, 100 \mathrm{ppb}$ and 150 $\mathrm{ppb}$ in three batches and calculated the $y$-intercept and slope. The decision limit (at á $=5 \%$ ) was calculated at permitted limit for all the compounds, the concentration at permitted limit (MRL) plus 1.64 times the standard deviation of the within-laboratory reproducibility. The results were given in table 9 .

Table. 7: Recovery/Accuracy

\begin{tabular}{lll}
\hline S.No. Compound $\quad$ Mean (Concentration in ppb) & $\begin{array}{l}\text { \% Recovery/Accuracy } \\
\text { (Concentration in ppb) }\end{array}$
\end{tabular}

\begin{tabular}{|c|c|c|c|c|c|c|c|}
\hline \multirow[b]{2}{*}{1} & \multirow{2}{*}{ 4-epi chlortetracycline } & \multirow{2}{*}{$\frac{\text { Batch -1 }}{43.2018}$} & \multirow{2}{*}{$\begin{array}{c}\text { Batch -2 } \\
44.8266\end{array}$} & \multirow{2}{*}{$\frac{\text { Batch -3 }}{42.5916}$} & \multirow{2}{*}{$\frac{\text { Batch -1 }}{86.40}$} & \multicolumn{2}{|c|}{ Batch -2 Batch -3 } \\
\hline & & & & & & 89.65 & 85.18 \\
\hline 2 & 4-epi oxytetracycline & 42.7798 & 42.7275 & 46.8627 & 85.56 & 85.45 & 93.73 \\
\hline 3 & 4-epi tetracycline & 41.7066 & 41.5344 & 41.5838 & 83.41 & 83.07 & 83.17 \\
\hline 4 & Chlortetracycline & 54.7178 & 54.5396 & 52.6245 & 109.44 & 109.08 & 105.25 \\
\hline 5 & Oxytetracycline & 53.2315 & 51.2158 & 50.6047 & 106.46 & 102.43 & 101.21 \\
\hline 6 & Tetracycline & 57.7920 & 55.6192 & 55.2160 & 115.58 & 111.24 & 110.43 \\
\hline
\end{tabular}


Detection Capability (CC $\beta$ )

Detection capability $(\beta=5 \%)$ was calculated, the concentration at decision limit plus 1.64 times the standard deviation of the 20 samples fortified at decision limit. The results were shown in table 9 and the recoveries of the 20 samples are meeting the criteria.
Table. 8: Ruggedness

\begin{tabular}{lllll}
\hline S.No. & Compound & Mean & SD $\%$ RSD \\
\hline 1 & 4-epi chlortetracycline & 43.54 & 1.67 & 3.84 \\
2 & 4-epi oxytetracycline & 44.12 & 2.89 & 6.55 \\
3 & 4-epi tetracycline & 41.61 & 0.91 & 2.18 \\
4 & Chlortetracycline & 53.96 & 2.10 & 3.89 \\
5 & Oxytetracycline & 51.68 & 1.76 & 3.40 \\
6 & Tetracycline & 56.21 & 2.19 & 3.90
\end{tabular}

Table. 9 : Decision limit (CC $\alpha$ ) and detection capability (CC $\beta)$

\begin{tabular}{llcc}
\hline S.No. & Compound & Decision limit $(\mathbf{C C} \boldsymbol{\alpha})$ & Detection capability (CC $\beta)$ \\
\hline 1 & 4-epi chlortetracycline & 114.4879 & 128.9759 \\
2 & 4-epi oxytetracycline & 111.8852 & 123.7703 \\
3 & 4-epi tetracycline & 108.6466 & 117.2932 \\
4 & Chlortetracycline & 114.8092 & 129.6185 \\
5 & Oxytetracycline & 109.4829 & 118.9658 \\
6 & Tetracycline & 108.2438 & 116.4877 \\
\hline
\end{tabular}

\section{CONCLUSIONS}

A simple positive ion LC-MS/MS method was developed and validated for the determination of tetracyline antibiotic residues in raw shrimp meat. Based on the results obtained, acceptance criteria for all validation parameters such as system suitability, specificity, calibration curve (Linearity), repeatability, within laboratory reproducibility, recovery, decision limit (CC $\alpha$ ) and detection capability (CC $\beta$ ) have been met for the method used to estimate the tetracylines in shrimp samples as per protocol and as well as EU guideline council Directive 2002/657/EC. The method requires only a small sample volume, needs minimal manual sample preparation and reasonable run time. For this reason, the method could be useful for determination of tetracylines in shrimp samples. Henceforth considered the method is validated and can be used for further intended purpose.

\section{ACKNOWLEDGEMENTS}

The author BSR thankful to authorities of S.V.University, Tirupati for their encouragement. The authors BSR and SY thankful to Management First Source Laboratory Solutions LLP (Analytical), Hyderabad for giving permission to carry out this work.

\section{REFERENCES}

1. Katiyar, S.K; Elend, T.D; Enhanced antiparasitic activity of lipophilic tetracyclines: role of uptake. Antimicrob. Agents Chemother. 1991, 35, 20752080.

2. Chopra, I; Hawkey, P.M; Hinton, M; Tetracyclines, molecular and clinical aspects. J. Antimicrob. Chemother., 1992, 29, 245-277.

3. Roberts, M.C; Tetracycline resistance determinants: mechanisms of action, regulation of expression, genetic mobility, and distribution. FEMS Microbiol. Rev., 1996. 19, 1-24.

4. Sczesny, S; Nau, H; Hamscher, G; Residue analysis of tetracyclines and their metabolites in eggs and in the environment by HPLC coupled with a microbiological assay and tandem mass spectrometry. Journal of Agricultural and Food Chemistry, 
2003, 51, 697-703

5. Frank, J.K; Patrick, S.C; Antibiotic resistance of bacteria from shrimp ponds, Aquaculture, 2001, 195(3-4), 193-204.

6. Oka, H; Ikai, Y; Ito, Y; Hayakawa, J; Harada, K; Suzuki, M; Odani, H; Maeda, K; J. Chromatogr. B., 1997, 693, 337.

7. Carson, M.C; Ngoh, M.A; Hadley, S.W; J. Chromatogr. B., 1998, 712, 113.

8. Cinquina, A.L; Longo, F; Anastasi, G; Giannetti, L; Cozzani, R; J. Chromatogr. A., 2003, 987, 227.

9. COMMISSION REGULATION (EU) No 37/2010 of 22 December 2009 on pharmacologically active substances and their classification regarding maximum residue limits in foodstuffs of animal origin

10. Andersen, W.C; Roybal, J.E; Gonzales, S.A; Turnipseed, S.B; Pfenning, A.P; Kuck, L.R; Determination of tetracycline residues in shrimp and whole milk using liquid chromatography with ultraviolet detection and residue confirmation by mass spectrometry. Analytica Chimica Acta, 2005, 529, 145-150.

11. Lee, J.B; Chung, H.H; Chung, Y.H; Lee, K.G; Development of an analytical protocol for detecting antibiotic residues in various foods. Food Chemistry, 2007, 105, 1726-1731.

12. Fletouris, D.J; Papapanagiotou, E.P; A new liquid chromatographic method for routine determination of oxytetracycline marker residue in the edible tissues of farm animals. Analytical and Bioanalytical Chemistry, 2008, 391, 1189-1198.

13. Tereza,T; Jana, O; Petr, N; Miroslav Flieger, High-throughput analysis of tetracycline antibiotics and their epimers in liquid hog manure using Ultra Performance Liquid Chromatography with UV detection, Chemosphere. 2010, 78, 353-359.

14. Fabio, G; Jorge, S; Fernando, G; and Cesar, R; A Novel Green Chemistry Method for Nonaqueous Extraction and HighPerformance Liquid Chromatography Detection of First-, Second-, and ThirdGeneration Tetracyclines, 4-Epitetracycline, and Tylosin in Animal Feeds, J. Agric. Food Chem. 2012, 60, 7121"7128

15. Yu, Liu; Hailan, Yang; Sheng, Y; Qiwei, H; Hongbo, C; Huiyu, L; Yinsheng, Qiu; High- performance liquid chromatography using pressurized liquid extraction for the determination of seven tetracyclines in egg, fish and shrimp, J. Chromatogr. B, 2013, 917, $11-17$.

16. Vinas, P; Balsalobre, N; Lopez-Erroz, C; Hernandez-Cordoba, M; Liquid chromatography with ultraviolet absorbance detection for the analysis of tetracycline residues in honey. J. of Chromatogr. A, 2004, 1022, 125-129.

17. Wen, Y; Wang, Y; Feng, Y.Q; Simultaneous residue monitoring of four tetracycline antibiotics in fish muscle by in-tube solidphase microextraction coupled with highperformance liquid chromatography. Talanta, 2006, 70, 153-159.

18. Fritz, J.W;Zuo, Y; Simultaneous determination of tetracycline, oxytetracycline, and 4epitetracycline in milk by high-performance liquid chromatography. Food Chemistry, 2007, 105, 1297-1301.

19. Schneider, M.J; Braden, S.E; Reyes-Herrera, I; Donoghue, D.J; Simultaneous determination of fluoroquinolones and tetracyclines in chicken muscle using HPLC with fluorescence detection.J. Chromatogra. B, 2007, 846, 8-13.

20. Maia, P.P; Rath, S; Reyes, F.G; Determination of oxytetracycline in tomatoes by HPLC using fluorescence detection. Food Chemistry, 2008, 109, 212-218.

21. Goto, T; Ito, Y; Yamadaa, S; Matsumoto, H; Okab, H; High-throughput analysis of tetracycline and penicillin antibiotics in animal tissues using electrospray tandem mass spectrometry with selected reaction monitoring transition.J. Chromatogra. A, 2005, 1100, 193-199.

22. Zhenfeng, Y; Yueming, Q; Xiuyun, L; Caini, J; Determination of multi-residues of tetracyclines and their metabolites in milk by high performance liquid chromatography-tandem positive-ion electrospray ionization mass spectrometry. Chinese Journal of Analytical Chemistry, 2006, 34, 1255-1259.

23. Granelli, K; Branzell, C; Rapid multi-residue screening of antibiotics in muscle and kidney by liquid chromatography-electrospray ionization-tandem mass spectrometry. Analytica Chimica Acta, 2007, 586, 289-295. 
24. Xu, J.Z;BinWu, T.D;Yang, W.Q;Zhang, X.Y; Liu,Y; Shen, C.Y; . Analysis of tetracycline residues in royal jelly by liquid chromatography-tandem mass spectrometry. J. Chromatogr. B, 2008, 868, 42-48.

25. Jing, T; Gao, X.D; Wang, P; Wang, Y; Lin, Y.F; Hu, $X . Z$; Determination of trace tetracycline antibiotics in foodstuffs by liquid chromatography-tandem mass spectrometry coupled with selective molecular-imprinted solid-phase extraction. Analytical and Bioanalytical Chemistry, 2009, 393, 2009-2018.

26. Venkates, P; Arun Kumar, N; Hari Prasad, R; Krishnamoorthy, K.B; Hari Prasath, K; Soumya, $\mathrm{V}$; LC/MS/MS analysis of tetracycline antibiotics in prawns (Penaeus monodon) from south India coastal region, Journal of Pharmacy Research, 2013, 6, 48-52.
27. Ewelina, P; Krzysztof, K; Analytical procedure for the determination of tetracyclines in medicated feeding stuffs by liquid chromatography-mass spectrometry, J Vet Res. 2016, 60, 35-41.

28. Jing-Jing, X; Mingrui, A; Rui, Yang; Zhijing, Tan; Jie, H; Jun, Cao; Li-Qing, P; Wan, C; Determination of Tetracycline Antibiotic Residues in Honey and Milk by Miniaturized Solid Phase Extraction using Chitosan-Modified Graphitized Multi-walled Carbon Nanotubes, J. Agric. Food Chem .2016, 30, 2647-54.

29. COMMISSION DECISION of 12 August 2002 implementing Council Directive 96/23/EC concerning the performance of analytical methods and the interpretation of results (notified under document number $\mathrm{C}(2002)$ 3044), (2002/657/EC) 